\title{
Assay of Dinitrotoluene on a Contaminated Soil Sample with an Anodic Stripping Peak Current
}

\author{
Suw-Young Ly, Chang-Hyun Lee* and Young-Sam Jung \\ Biosensor Research Institute, Seoul National University of Technology, Seoul 139-743, Korea \\ Division of General Education. Pyeongtaek University, Pyeongtaek 450-701, Korea \\ (Manuscript received 30 October, 2006; accepted 13 November, 2006)
}

This report presents a voltammetric assay of dinitrotoluene using a DNA immobilized onto a carbon nanotube paste electrode (PE). The cyclic voltammetry (CV) and square wave (SW) stripping voltammetry parameters of the optimized conditions were obtained. An anodic peak current appeared at $0.3 \mathrm{~V}$ (versus $\mathrm{Ag} / \mathrm{AgCl}$ ) in a $0.1-\mathrm{M} \mathrm{NH}_{4} \mathrm{H}_{2} \mathrm{PO}_{4}$ electrolyte solution. The detection limit was found to be $0.6 \mathrm{ngL}^{-1}(\mathrm{~S} / \mathrm{N}=10)$, within a deposition time of $100 \mathrm{sec}$.

Key Words: Voltammetry, DNA, Dinitrotoluene, Anodic

\section{Introduction}

Dinitrotoluene (DNT) is producedby mixing toluene with nitric acid [1] in the presence of sulfuric acid, which will result in the formation of $80 \% 2,4$ - DNT and 20\% 2,6- DNT [2]. 2,4- DNT is very explosive and highly reactive, whereas $2,6-$ DNT does not evaporate [2]. DNT is one of the most widely produced military explosives [3,4,5 and 6] all over the world, and it has a particularly well-developed market due to the importance of explosive compounds of 2,4,6TNT, 2,4- DNT and 2,6- DNT [7-8]. As its development grew, the problems it might cause have elicited increasing concerns. Explosive compounds remain in the environment [5, 6 and 9], especially in the physical and chemical properties of soil [10,11 and 12]. There has been a growing concern that contamination from firing ranges can adversely affect the health of people [13-14]. DNT is also easily adsorbed through the skin, thus exposing humans to its harmful health effects [9]. Detection of DNT is being developed with a variety of sensors, as a result of which the concentrations of DNT are approximately 25 times higher than those of TNT $\{148$ parts-per-billion (ppb) compared to $6 \mathrm{ppb}\}$ [15]. To detect DNT, a few methods

Corresponding Author : Chang-Hyun Lee, Division of General Education, Pyeongtaek University, Pyeongtaek 450-701, Korea

Phone: +82-31-658-1565

E-mail: lch@ptu.ac.kr have been used, including the $\mathrm{THz}$ (terahertz) time-domain spectroscopy (THz-TDS), Fourier transform infrared spectroscopy (FTIR) [11 and 16], and high-performance liquid chromatography (HPLC) [17 and 18]. An FTIR spectroscopic investigation of 2,4-DNT in the $0.2-19.5 \mathrm{THz}$ range was performed [11]. The objective of the study was to detect 2,4- and 2,6- DNT in contaminated soil using the voltammetric method. At first, contaminated soil was collected at a firing range. The DNT concentration in the soil was $1 \mathrm{~g}$ in $100 \mathrm{~mL}$ of distilled water (previous results). there have been a few reported studies on DNT chemical voltammetric methods. Therefore, the authors used chemical voltammetric methods to determine the presence of DNT in the soil sample at a simple methods and obtained successful results, which had a very low detective limit at the ppt level.

Carbon nanotubes have been developed due to their electronic and chemical properties, [19-20]. Since the unique electrical properties of nanotubes -i.e., high conductivity [20-22], chemical inertness, and mechanical strength and stability [23] in harsh chemical environments [21] for biosensors [24], have been reported, excellent improvements have been demonstrated [24-25]. Carbon nanotubes enable highly sensitive detection of DNT The study presented here describes the use of carbon nanotube paste electrodes (CNTPE) mixed with DNA(Deoxyribonuclic acid) to determine 
the electrochemical behavior [25] of dinitrotoluene. The combination of CNT with DNA has been gaining increasing attention recently due to its capacity to reach a lower detection limit [20 and 23]. Therefore, the authors researched on the peak current of dinitrotoluene using the CNT-mixed-with-DNA method and successfully lowered the detection limit of DNT to $0.6 \mathrm{ngL}^{-1}$. The method can be applied to the soil assay related to explosive materials.

\section{Experiment}

\subsection{Apparatus, Reagents, and Procedure}

All voltammetric experiments were performed using a $\mathrm{CHI} 660 \mathrm{~A}$ instrument electrochemical workstation (from $\mathrm{CH}$ Instruments, Inc., Cordova, TN, USA).

To prepare the PE $40 \%$ nanotube graphite powder (from Nanostructured \& Amorphous Materials, Inc.) and $40 \%$ DNA (double-stranded and prepared from calf thymus sigma) was mixed with $20 \%$ mineral oil. The mixture was homogenized in a mortar for 30 minutes. The mixed paste was inserted into a plastic syringe needle using a 3-mm-diameter, then copper wire was connected to the electrichemical measurements systems.

A three-electrode system was used to detect the voltammetric signal. The PE electrode was used with saturated $\mathrm{Ag} / \mathrm{AgCl} / \mathrm{KCl}$ as the reference electrode, and with a platinum auxiliary electrode. The experimental solution was prepared using double-distilled water (18 Mega Ohm. $\mathrm{Cm}^{-1}$ ). The standard and other reagents obtained from Aldrich(analytical reagent grade ) were diluted as needed. The electrolyte solutions of the acid and base buffer (all in $0.1 \mathrm{M}$ ) were initially examined to search for a possible supporting electrolyte solution. As a result, a $0.1-\mathrm{M}$ phosphate buffer solution was found to be the most suitable. Its ionic strength was examined within the range of 0.01-0.3 M. The 0.1-M ionic solution was found to have the most suitable concentration. To determine the peak potential, cyclic voltammograms were conducted at a scan rate of $0.5 \mathrm{Vs}^{-1}$. An oxidation peak potential of $0.3 \mathrm{~V}$ was obtained, at which condition various stripping parameters were sought to determine the more sensitive detection ranges. The cyclic voltammetry potential range of $-1.1 \mathrm{~V}$ at the scan rate of $0.5(\mathrm{~V} / \mathrm{sec})$ with 14 repeate was scanned for the immobilization of DNA onto the carbon nanotube surface. The three-electrode system was then immersed in a $15-\mathrm{mL}$ cell.

\section{Results}

\subsection{Concentration effects of cyclic voltammetry}

First, in cyclic voltammetry, various concentration ranges were tested with a scan rate of $0.5 \mathrm{Vs}^{-1}$, an initial potential of $-1.0 \mathrm{~V}$, and a switching potential of $1.0 \mathrm{~V}$ using a $0.1-\mathrm{M}$ ammonium phosphate electrolyte solution so that analytical peak potentials could be examined with a wide potential window. Fig. 1 shows the test results. As no signals appeared in the blank electrolyte solution, a small amount of 2 -ugL ${ }^{-1}$ dinitrotoluene was spiked at these conditions and a small oxidation peak was obtained at $0.3 \mathrm{~V}$, but the reduction peak was hardly found. Thus, more increased concentrations were spiked from 2 to 40 $\mathrm{ugL}^{-1}$ of dinitrotoluene, and a linearly increasing working curve was obtained with a slop sensitivity of $\triangle \mathrm{x} / \triangle \mathrm{y}=0.1119$ and a precision of $\mathrm{R}^{2}=0.992$ $(\mathrm{N}=14)$. Under optimum conditions, the anodic maximum peak current was found to be $4.71 \times$ $10^{-7} \mathrm{~A}$ at a dinitrotoluene concentration of $40 \mathrm{ugL}^{-1}$. This result can be applied in the analytical field.

\subsection{Optimizations of SW Parameters}

Fig. 2 (A) shows the various SW frequency parameters used, from 300 to $1,000 \mathrm{~Hz}$. From 300 to $400 \mathrm{~Hz}$, the peak current increased, after which the

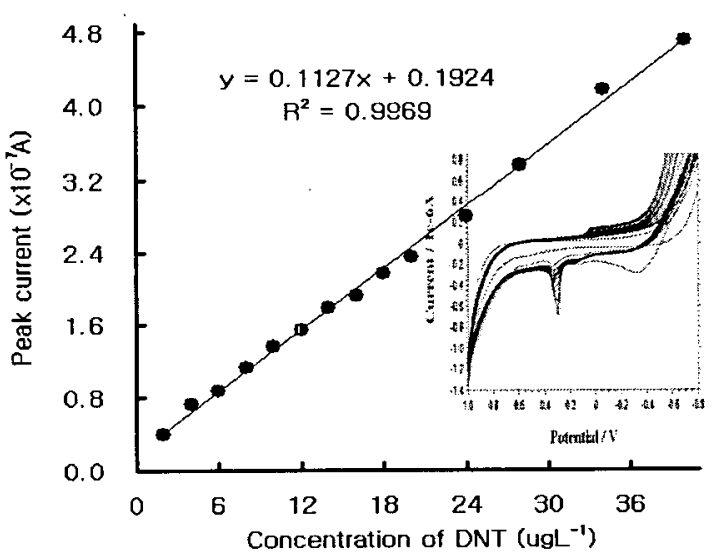

Fig. 1. The working curve and its voltammogram using cyclic voltammetry according to dinitrotoluene concentrations of $2,4,6,8,10,12,14,16,18,20,24,28$. 24. 47 and $40 \mathrm{ugL}^{-1}$ in a $0.1-\mathrm{M} \mathrm{NH}_{4} \mathrm{H}_{2} \mathrm{PO}_{4}$ solution at the scan rate of $0.5 \mathrm{Vs}^{-1}$. 


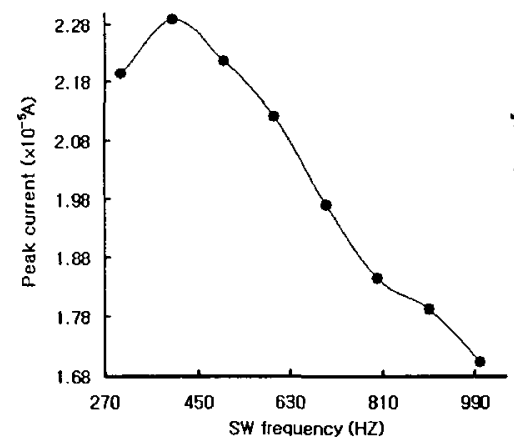

(A)

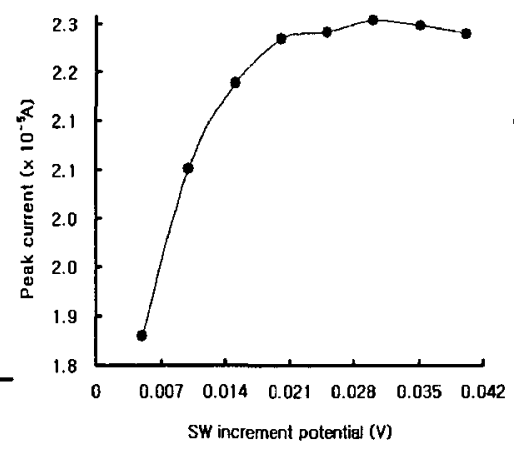

(B)

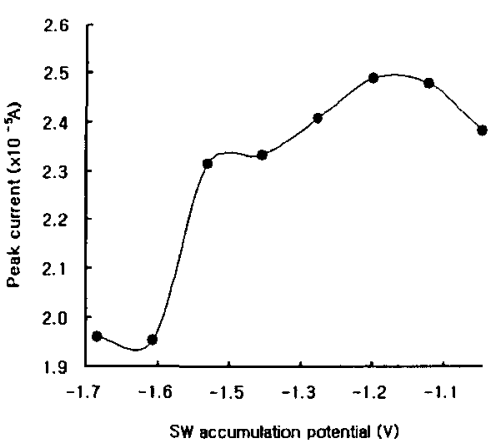

(C)

Fig. 2. Oxidation square wave (A) frequencies of $300,400,500,600,700,800,900$ and 1,000 Hz. (B) Increment potentials of $0.005,0.01,0.015,0.02,0.025,0.03,0.035$ and 0.04 V. (C) Initial potentials of $-1.0,-1.1,-1.2,-1.3,-1.4$, $-1.5,-1.6$ and $-1.7 \mathrm{~V}$. Other parameters were of Fig. 4.

peak current sharply decreased up to $1,000 \mathrm{~Hz}$. Thus, at $400 \mathrm{~Hz}$, the maximum response of $2.2289 \times 10^{-5} \mathrm{~A}$ appeared. In this test, the amplitude and the increment were pegged at 0.45 and 0.04 , respectively. In Fig. 2 (B), the SW stripping increment potentials were examined at the $0.005-0.04 \mathrm{~V}$ range with 8 points. The signal shown in the voltammogram (not shown in this figure) constantly increased. The maximum peak current of $0.03 \mathrm{~V}$ was obtained at $2.264 \times 10^{-5} \mathrm{~A}$, after which it decreased slowly up to $0.04 \mathrm{~V}$. Fig. 2 (C) showed an initial potential from -1.0 to $-1.7 \mathrm{~V}$, manifesting irregular changes. Beginning with $-1.0 \mathrm{~V}$, the peak current gradually increased to $-1.2 \mathrm{~V}$, then decreased to $-1.6 \mathrm{~V}$. Between $-1.5 \mathrm{~V}$ and $-1.6 \mathrm{~V}$, the peak current was very rapidly indicated. At $-1.2 \mathrm{~V}$, the $2.49 \times 10^{-5} \mathrm{~A}$ peak current reached its maximum peak. Although not presented in this study, the $\mathrm{SW}$

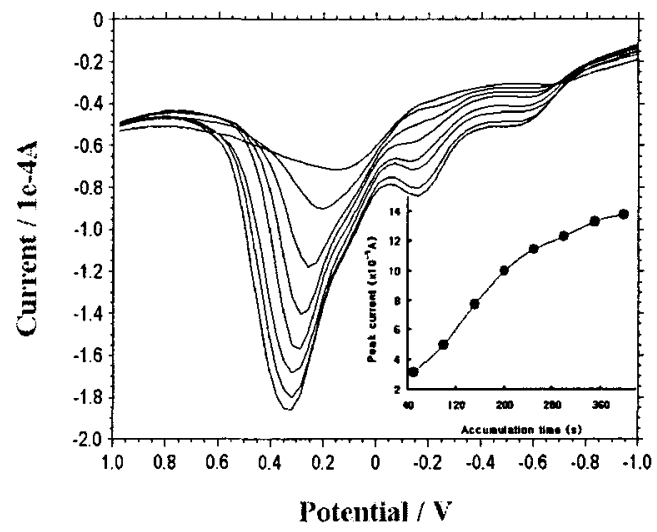

(A) amplitude was examined to determine the peak current ranging from 0.1 to $0.45 \mathrm{~V}$. The maximum peak was obtained at $18.4 \times 10^{-6} \mathrm{~A}$ in $0.45 \mathrm{~V}$, which was more sensitive than any other parameter and which showed a constantly increasing peak width.

3.3. SW accumulation times and electrolyte $\mathrm{pH}$ efftects

Fig. 3 (A) shows the experimental results of this study's test of the stripping voltammetric parameters of various accumulation times in the range of $50-400 \mathrm{sec}$. The experimental peak current increased linearly; and at $400 \mathrm{sec}$, a maximum peak current of $13.8 \times 10^{-5} \mathrm{~A}$ was obtained, which was more sensitive than the $\mathrm{pH}$ effects, whereas the peak widths were constant and narrowly appeared. Other experiments, however, used a short 100 -sec accumulation time to save time. Fig. 3 (B) shows the stripping voltammetric peak current in

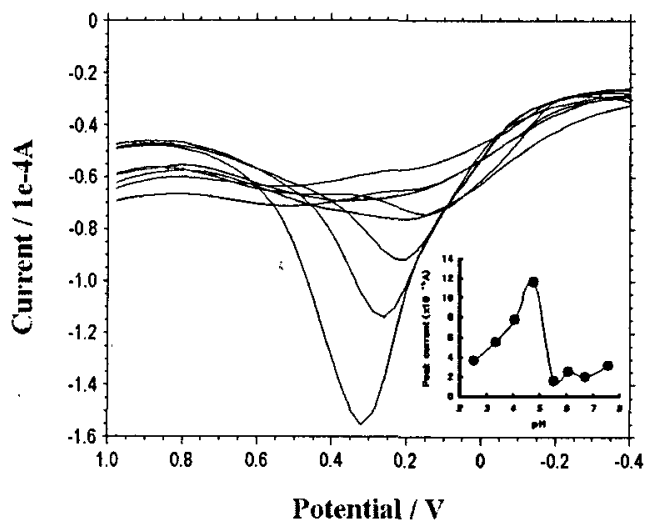

(B)

Fig. 3. (A) SW stripping anodic accumulation peak currents for $50,100,150,200,250,300,350$ and 400 sec. (B) Various $\mathrm{pH}$ peak currents $(2.54,3.36,4.06,4.77,5.54,6.08,6.71$ and 7.59$)$ in $22-\mathrm{mgL}^{-1}$ dinitrotoluene. Other parameters were of Fig. 4. 
$2 \mathrm{mgL}^{-1}$ of concentrated dinitrotoluene within the $\mathrm{pH}$ range of 2.54-7.59. This $\mathrm{pH}$ accumulation peak current non-linearly appeared with a wide peak width. At the $\mathrm{pH}$ range of 2.54-4.77, a linearly increasing working curve was indicated, after which all of a sudden, it started to fall down very sharply. Other ranges repeatedly increased and decreased, and the maximum peak current of $4.77 \times 105 \mathrm{~A}$ at the $\mathrm{pH}$ of 4.77 appeared. Thus, all other $\mathrm{SW}$ parameters were used with a $4.77 \mathrm{pH}$ strength.

\subsection{Analytical applications and Statistics}

Finally, the optimized parameters were used to -detect the working concentration range of $2-19.5 \mathrm{ngL}^{-1}$ of dinitrotoluene. At these conditions, the linear equation $y=0.5261 x+0.7816$ and the precision of $R^{2}=0.9947$ were calculated, and showed a gradually increasing linear curve. As shown in Fig. 4 (A), its voltammogram illustrated regular changes in its peak sharp, the response of which was very sensitive with a narrowed peak width. The maximum peak current of $10.72 \times 10^{-6}$ $\mathrm{A}$ at $20 \mathrm{ngL}^{-1}$ of concentrated dinitrotoluene was obtained, and its peak increased sharply. At these conditions, the relative standard deviation (RSD) was found to be 0.9947 at a $100-\mathrm{s}^{-1}$ accumulation time, and the estimated detection limit was $0.6 \mathrm{ngL}^{-1}$ on the basis of the signal-to-noise ratio $(S / N=3)$. Then the analytical application of the sand from the firing range was examined for the known concentration of the $0.1-\mathrm{mL}$

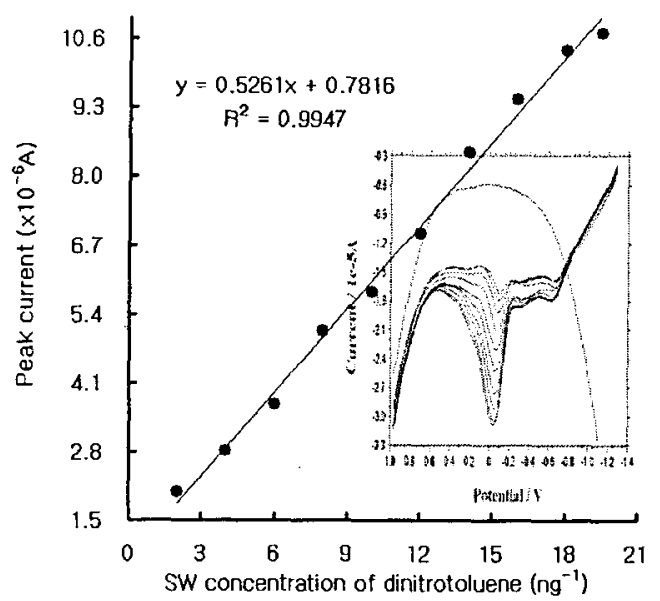

Fig. 4. (A) SW concentration effect of a stripping voltammogram and its working curve for 2-, 4-, 6-, 8-, $10_{-}^{-}, 12-, 14-, 16-, 18-$ and $20-\mathrm{nLL}^{-1}$ dinitrotoluene in $0.1 \mathrm{M}$ of $\mathrm{NH}_{4} \mathrm{H}_{2} \mathrm{PO}_{4}$ at a deposition time of 100 sec. Other parameters were of optimum paramitters. soil solution, and using the standard addition method, the results was calculated with a $0.6-\mathrm{mgL}^{-1} / \mathrm{lg}$ soil sample. This application test was carried out five times under optimum conditions. The results were satisfactory at $0.59 \mathrm{mgL}^{-1}$, with a $95.5 \%(\mathrm{n}=5)$ recovery. Several other interferences were also examined, such as metal ions and their similar kinds of explosion materials, under these optimized conditions. At the spike of $1 \mathrm{mgL}^{-1}$ of dinitrotoluene, the existence of $10 \mathrm{mgL}^{-1}$ of $\mathrm{Ba}(\mathrm{II})$, $\mathrm{Cr}$ (III), $\mathrm{Co}(\mathrm{III}), \mathrm{Hg}(\mathrm{II}), \mathrm{Bi}(\mathrm{I}), \mathrm{Cd}(\mathrm{II}), \mathrm{Ge}(\mathrm{IV}), \mathrm{RDX}$, dinitrobenzene, and $99 \%$ dinitrotoluene resulted in $218.28 \%,-67.98 \%, 10.95 \%, 171.86 \%, 14.07 \%, 10.87 \%$, $10.55 \%, 0.23 \%, 498.52 \%$, and $43.88 \%$, respectively. The results showed that dinitrobenzene in similar explosive materials responded most sensitively. The presence of other interference ions was also effectively corrected using standard addition methods.

\section{Conclusion}

This paper describes the identification of optimized conditions for determining dinitrotoluene in contaminated soil sample using the voltammetric method. This method was found to be viable and stable in various analytical conditions for $\mathrm{SW}$, and to be more sensitive than other common voltammetric methods. The results presented lower detection limits in nanogram ranges. This indicates that the voltammetric method could be usable to assay in environmental materials and could be applicable in other fields that requiring explosive analysis

\section{Acknowledgement}

This paper was supported by the Research Fund, 2004 Pyongtaek University of Korea

\section{References}

1) Chen, W. S., C. N. Juan and K. M. Wei, 2005, Recovery of High-purity 2,4-Dinitrotoluene from Spent Mixed Acid in the Toluene Nitration Process Separation and Purification Technology, 41; 57-63.

2) Gupta, G. and H. Bhaskaran, 2004, Short Communication Use of Poultry Litter for the Biodegradation of Soil Contaminated with 2,4- and 2,6Dinitrotoluene, Journal of Hazardous Materials, B116, 167-171.

3) Boopathy, R., 2002, Effect of Food-grade Surfactants on the Bioremediation of Explosives con- 
taminated Soil, Journal of Hazardous Materials, 92, 103-114.

4) Borch, T. and R. Gerlach, 2004, Use of Reversedphase, High-performance Liquid-chromatographydiode Array Detection for the Complete Separation of 2,4,6-Trinitrotoluene Metabolites and the EPA Method 8330 Explosives: Influence of Temperature and an Ion-pair Reagent, Journal of Chromatography, A, 1022, 83-94.

5) Abramov, V. O., O. V. Abramov, A. E. Gekhman, V. M. Kuznetsov and G. J. Price, 2005, Ultrasonic Intensification of Ozone and Electrochemical Destruction of 1,3-Dinitrobenzene and 2,4-Dinitrotoluene, Ultrasonics Sonochemistry.

6) Sponza, D. T., H. Atalay, 2005, Simultaneous Phosphorus, Nitrogen and Dinitrotoluene Removals in Batch Anaerobic/Anoxic/Aerobic Sequentials, Process Biochemistry, 40, 25-34.

7) Chen, W. S., C. N. Juan and K. M. Wei, 2005, Mineralization of Dinitrotoluene and Trinitrotoluene of Spent Acid in the Toluene Nitration Process by Fenton Oxidation, Chemosphere, 60, 1072-1079.

8) Chen, W. S., C. N. Juan and K. M. Wei, 2005, Recovery of Dinitrotoluene and Trinitrotoluene from Spent Acid in the Toluene Nitration Process Using the Solvent Extraction, Separation and Purification Technologies, 43, 95-101.

9) Honeychurch, K. C., J. P. Hart, P. R. J. Pritchard, S. J. Hawkins and N. M. Ratcliffe, 2003, Development of an Electrochemical Assay for 2,6-Dinitrotoluene Based on a Screen-printed Carbon Electrode and Its Potential Application in Bioanalysis and Occupational and Public Health, Biosensors and Bioelectronics, 19, 305-312.

10) Shin, K. H., Y. Lim, J. H. Ahn, J. Khil, C. J. Cha and H. G. Hur, 2005, Anaerobic Biotransformation of Dinitrotoluene Isomers by Lactococcus Lactis Subsp, Lactis Strain 27 Isolated from Earthworm Intestines, Chemosphere.

11) Chen, Y., H. Liu, Y. Deng, D. Schauki, M. J. Fitch, R. Osiander, C. Dodson, J. B. Spicer, M. Shur and X. C. Zhang, 2004, THz Spectroscopic Investigation of 2,4-Dinitrotoluene, Chemical Physics Letters, 400, 357-361.

12) Walsh, M. E., 2001, Determination of Nitroaromatic, Nitramine and Nitrate Ester Explosives in Soil Using Gas Chromatography and an Electron
Capture Detector, Talanta, 54, 427-438.

13) Asbury, G. R., J. Klasmeier and H. H. Hill, 2000, Jr. Analysis of Explosives Using Electrospray Ionization:Ion Mobility Spectrometry (ESI:IMS), Talanta, 50, 1291-1298.

14) Clausen, J., J. Robb, D. Curry and N. Korte, 2004, A Case Study of Contaminants on Military Ranges: Camp Edwards, Massachusetts, USA. Environmental Pollution, 129, 13-21.

15) Pinnaduwage, L. A., T. Thundat, J. E. Hawk, D. L. Hedden, P. F. Britt, E. J. Houser, S. Stepnowski, R. A. McGill and D. Bubb, 2004, Detection of 2,4-Dinitrotoluene Using Microcantilever Sensors, Sensors and Actuators, B 99, 223-229.

16) Weese, R. K., J. L. Maienschein and C. T. Perrino, 2003, Kinetics of the $\beta \rightarrow \delta$ Solid-Solid Phase Transition of HMX, Octahydro- 1,3,5,7- tetranitro1,3,5,7- tetrazocine, Thermochimica Acta, 401, $1-7$.

17) Zhang, C., R. C. Daprato, S. F. Nishino, J. C. Spain and J. B. Hughes, 2001, Remediation of Dinitrotoluene-contaminated Soils from Former Ammunition Plants: Soil Washing Efficiency and Effective Process Monitoring in Bioslurry Reactors, Journal of Hazardous Materials, B87, 139-154.

18) Groom, C. A., S. Beaudet, A. Halasz, L. Paquet and J. Hawari, 2001, Detection of the Cyclic Nitramine Explosives Hexahydro-1,3,5- trinitro-1,3,5-triazine (RDX) and Octahydro- 1,3,5,7tetranitro- 1,3,5,7- tetrazine (HMX) and of their Degradation Products in Soil Environments, Journal of Chromatography, A 909, 53-60.

19) Dovbeshko, G. I., O. P. Repnytska and E. D. Obraztsova, 2003, Y.V. Shtogun, DNA Interaction with Single- walled Carbon Nanotubes: A SEIRA Study, Chemical Physics Letters, 372, 432-437.

20) M. Guo, J. Chen, D. Liu, L. Nie and S. Yao, 2004, Electrochemical Characteristics of the Immobilization of Calf Thymus DNA Molecules on Multiwalled Carbon Nanotubes. Bioelectrochemistry, 62, 29-35.

21) Sherigara, B. S., W. Kutner and F. D'Souza, 2003, Electrocatalytic Properties and Sensor Applications of Fullerenes and Carbon Nanotubes, Electroanalysis, 9, 15.

22) Wang, J., M. Li, Z. Shi, N. Li and Z. Gua, 2004, Electrochemistry of DNA at Single-walled Carbon 
Nanotubes, Electroanalysis, 1, 16.

23) Kerman, K., Y. Morita, Y. Takamura, M. Ozsoz and E. Tamiya, 2004, DNA-directed Attachment of Carbon Nanotubes for Enhanced Label-free Electrochemical Detection of DNA Hybridization. Electroanalysis, 20, 16.

24) Joseph, N., M. Barisci, G. Tahhan, G. Wallace,
S. Badaire, T. Vaugien, M. Maugey and P. Poulin, Properties of Carbon Nanotube Fibers Spun from DNA- stabilized Dispersions.

25) Pedano, M. L and G. A. Rivas, 2004, Adsorption and Electrooxidation of Nucleic Acids at Carbon Nanotube Paste Electrodes, Electrochemistry Communications,s6, 10-16. 